\title{
MicroRNA-320a is downregulated in non-small cell lung cancer and suppresses tumor cell growth and invasion by directly targeting insulin-like growth factor 1 receptor
}

\author{
JIANGUO WANG ${ }^{1,2}, \mathrm{CHUNYUN} \mathrm{SHI}^{3}$, JIANFEI WANG ${ }^{4}$, LI CAO $^{4}$, LI ZHONG $^{4}$ and DONGMEI WANG ${ }^{1}$ \\ ${ }^{1}$ College of Life Sciences, Agricultural University of Hebei; ${ }^{2}$ Clinical Laboratory, \\ Affiliated Hospital of Hebei University, Baoding, Hebei 071001; ${ }^{3}$ Department of Pediatrics, \\ Baoding Children's Hospital; ${ }^{4}$ College of Life Sciences, Hebei University, Baoding, Hebei 071000, P.R. China
}

Received December 23, 2015; Accepted December 16, 2016

DOI: $10.3892 / \mathrm{ol} .2017 .5863$

\begin{abstract}
Accumulating evidence has demonstrated that microRNAs (miRs/miRNAs) are implicated in carcinogenesis and cancer progression, and can function as oncogenes or tumor suppressor genes in human cancer types. Previous profile studies of miRNA expression levels have revealed that miR-320a was downregulated in breast cancer, colon cancer, bladder cancer, glioblastoma and salivary adenoid cystic carcinoma. However, its expression level, potential functions and the mechanisms underlying its functions in non-small cell lung cancer (NSCLC) require further investigation. The present study investigated the expression level, biological roles and underlying molecular mechanisms of miR-320a in NSCLC. The expression levels of miR-320a in NSCLC tissue and cell lines were detected using the reverse transcription-quantitative polymerase chain reaction. Cell proliferation and Transwell invasion assays were performed to examine the effects of miR-320a on NSCLC cells. In addition, bioinformatic analysis, western blot analysis and luciferase reporter assays were performed to identify the direct gene target of miR-320a in NSCLC. In the present study it was demonstrated that miR-320a was significantly downregulated in NSCLC tissues and cell lines. Ectopic overexpression of miR-320a suppressed the proliferation and invasion of NSCLC cells. Further studies indicated that miR-320a directly targeted the 3'-untranslated region of insulin-like growth factor 1 receptor (IGF-1R) and suppressed its expression at the mRNA and protein levels. As well as restoring the miR-320a expression level, the knockdown of IGF-1R also decreased the growth and invasion of the NSCLC cells. These results suggested that miR-320a served as
\end{abstract}

Correspondence to: Professor Dongmei Wang, College of Life Sciences, Agricultural University of Hebei, 2596 Lekan Road, Baoding, Hebei 071001, P.R. China

E-mail: agr_dongmeiwang@163.com

Key words: microRNA-320a, non-small cell lung cancer, insulin-like growth factor 1 receptor, growth, invasion a tumor suppressor in the NSCLC cells by directly targeting IGF-1R. Therefore, miR-320a should be investigated as a therapeutic target for the treatment of NSCLC.

\section{Introduction}

Human lung cancer is the most frequently occurring malignant tumor and the leading cause of cancer-associated mortality worldwide (1). In 2015, it was estimated that there would be 221,200 novel cases and 158,040 mortalities due to lung cancer in the United States of America (2). Epidemiological studies have demonstrated that a number of closely-associated risk factors contribute to the carcinogenesis and progression of lung cancer, including environmental pollution, smoking and occupational carcinogens (3-6). Lung cancer has become a common malignancy, particularly in China, mainly due to the increased rate of cigarette smoking and environmental pollution (7). Non-small cell lung cancer (NSCLC), the predominant category of lung cancer, accounts for $\sim 85 \%$ of all cases (8). According to its histology, NSCLC may be divided into three subtypes: Squamous-cell carcinoma, adenocarcinoma and large-cell carcinoma (9). Despite improvements in traditional treatments, including surgery, followed by radiotherapy and/or chemotherapy, the prognosis of NSCLC remains poor, with a 5 -year overall survival rate of $10-15 \%(10,11)$. Therefore, an improved understanding of the molecular mechanisms underlying the progression of NSCLC would be of benefit to the investigation of novel therapeutic targets and would improve the prognosis of patients with NSCLC.

The microRNAs (miRs/miRNAs) are a family of endogenous, short and non-coding molecules inhibiting the translation or degradation of target genes by combining with the complementary sequences in the 3'-untranslated region (3'UTR) of target genes (12). An miRNA may regulate numerous target genes and one gene may be regulated by multiple miRNAs. Therefore, $>60 \%$ of all human genes have been predicted to be regulated by miRNAs (13). The genes modulated by miRNAs have been reported in various types of physiological processes. Thus, miRNAs serve critical regulatory roles in diverse biological processes, including proliferation, apoptosis, migration, invasion, metastasis, cell differentiation and 
metabolism $(12,14,15)$. A previous study revealed that miRNAs may function as oncogenes or tumor suppressors during tumor development and progression, depending on the roles of their target genes, and that they are aberrantly expressed in a number of human cancer types, including bladder cancer (16), colorectal cancer (17), gastric cancer (18) and glioma (19). In conclusion, these findings indicated that miRNAs demonstrate potential as efficient therapeutic targets for cancer treatment.

In the present study, the expression level of miR-320a in NSCLC tissues and cell lines was determined, and the functions of miR-320a in NSCLC cells was evaluated. Furthermore, the molecular mechanisms underlying its functions in NSCLC cells were also investigated.

\section{Materials and methods}

Ethics statement and tissue samples. The present study was approved by the Ethical Committee of the Affiliated Hospital of Hebei University (Baoding, Hebei, China). All patients provided written consent and were informed of the purposes of the present study. Between October 2013 and February 2015, NSCLC tissues and the matched adjacent tissues (normal tissues) were collected from 32 patients (19 male and 13 female; age range, 41-69 years) with NSCLC who had undergone surgical resection at the Affiliated Hospital of Hebei University (China). All the tissue samples were immediately snap-frozen in liquid nitrogen and stored at $-80^{\circ} \mathrm{C}$.

Cell culture and oligonucleotide transfection. The HEK293T cell line, human NSCLC H23, H522, SPC-A1 and A549 cell lines, and the 16HBE normal bronchial epithelial cell line were purchased from the American Type Culture Collection (Manassas, VA, USA). These cell lines were maintained in RPMI-1640 (Gibco; Thermo Fisher Scientific, Inc., Waltham, MA, USA) or Dulbecco's modified Eagle's medium (DMEM; Gibco; Thermo Fisher Scientific, Inc.) supplemented with $10 \%$ fetal bovine serum (FBS; Gibco; Thermo Fisher Scientific, Inc.) at $37^{\circ} \mathrm{C}$ in $5 \% \mathrm{CO}_{2}$ in a cell incubator.

miR-320a mimics, negative control mimics (NC) and luciferase report vectors [PGL3-IGF-1R-3'UTR wild-type (Wt) and PGL3-IGF-1R-3'UTR mutation (Mut)] were synthesized by Shanghai GenePharma Co., Ltd. (Shanghai, China). Insulin-like growth factor 1 receptor (IGF-1R) small interfering (si)RNA and control (ctrl) siRNA were obtained from Guangzhou Ribobio Co., Ltd. (Guangzhou, China). Cell transfection was performed using Lipofectamine ${ }^{\circledR} 2000$ (Invitrogen; Thermo Fisher Scientific, Inc.) according to the manufacturer's protocol.

RNA isolation and reverse transcription-quantitative polymerase chain reaction $(R T-q P C R)$. Total RNA was extracted from the tissues and cell lines using TRIzol ${ }^{\circledR}$ (Invitrogen; Thermo Fisher Scientific, Inc.), according to the manufacturer's protocol. Quantification of total RNA was determined using a Nanodrop ${ }^{\circledR}$ ND-1000 spectrophotometer (NanoDrop Technologies; Thermo Fisher Scientific, Inc., Pittsburgh, PA, USA). Total RNA was synthesized into cDNA using the TaqMan ${ }^{\circledR}$ MicroRNA Reverse Transcription kit (Applied Biosystems; Thermo Fisher Scientific, Inc.). The procedure for reverse transcription was as follows: $16^{\circ} \mathrm{C}$ for
$30 \mathrm{~min} ; 42^{\circ} \mathrm{C}$ for $30 \mathrm{~min}$, and $85^{\circ} \mathrm{C}$ for $5 \mathrm{~min}$. The expression level of miR-320a was quantified using the TaqMan ${ }^{\circledR}$ miRNA assay (Applied Biosystems; Thermo Fisher Scientific, Inc.). The qPCR was performed using 40 cycles of denaturation at $95^{\circ} \mathrm{C}$ for $15 \mathrm{sec}$ and annealing/extension at $60^{\circ} \mathrm{C}$ for $60 \mathrm{sec}$. U6 served as an endogenous control for miR-320a expression. The SYBR $^{\circledR}$-Green RT-PCR kit (Takara Bio, Inc., Otsu, Japan) was used to determine the IGF-1R mRNA expression level, with GADPH as an internal control. The cycling conditions were as follows: $42^{\circ} \mathrm{C}$ for $5 \mathrm{~min} ; 95^{\circ} \mathrm{C}$ for $10 \mathrm{sec}$; and 40 cycles of $95^{\circ} \mathrm{C}$ for $5 \mathrm{sec}, 55^{\circ} \mathrm{C}$ for $30 \mathrm{sec}$ and $70^{\circ} \mathrm{C}$ for $30 \mathrm{sec}$. Each sample was analyzed in triplicate. The relative expression of miR-320a and IGF-1R mRNA was analyzed by use of the $2^{-\Delta \Delta \mathrm{Cq}}$ method (20).

Cell proliferation assay. The cell proliferation assay was performed using the MTT (Sigma-Aldrich; Merck Millipore, Darmstadt, Germany) method. Following $24 \mathrm{~h}$ of transfection, the cells were collected and re-seeded into 96-well plates at a density of 3,000 cells/well. The cell proliferation assays were performed every $24 \mathrm{~h}$. In brief, $20 \mu \mathrm{l}$ MTT solution $(5 \mathrm{mg} / \mathrm{ml})$ was added to DMEM supplemented with $10 \%$ FBS and incubated for a further $4 \mathrm{~h}$ at $37^{\circ} \mathrm{C}$. Subsequently, the culture medium was removed and the remaining formazan precipitates were dissolved in $150 \mu \mathrm{l}$ dimethylsulfoxide (Sigma-Aldrich; Merck Millipore). The optical density values of each well were detected at a wavelength of $490 \mathrm{~nm}$. This assay was performed in triplicate.

Transwell cell invasion assay. The cell invasion ability was evaluated using the Transwell cell invasion assay with Transwell plates coated with Matrigel (BD Biosciences, San Jose, CA, USA). At $48 \mathrm{~h}$ post-transfection, the cells were collected and resuspended in FBS-free DMEM. Transfected cells $\left(1 \times 10^{5}\right)$ were added to the upper chamber of the Transwell plates and $500 \mu \mathrm{l}$ culture medium supplemented with $20 \%$ FBS was added to the lower portion of the chamber. Following incubation for $48 \mathrm{~h}$ at $37^{\circ} \mathrm{C}$, the non-invading cells were carefully removed using cotton wool. The cells that invaded the lower surface of the Transwell membrane were fixed with $95 \%$ ethanol, stained with $0.1 \%$ crystal violet (Beyotime Institute of Biotechnology, Haimen, China) and quantified under a light microscope.

Western blot analysis. The total protein was isolated from the transfected cells and the concentration of total protein was determined using the Pierce bicinchoninic acid assay (Thermo Fisher Scientific, Inc.). Equal amounts of protein (20 $\mu \mathrm{g} / \mathrm{lane})$ were fractionated by SDS-PAGE on a $10 \%$ gel and transferred to polyvinylidene fluoride membranes (Bio-Rad Laboratories, Inc., Hercules, CA, USA). The membranes were blocked using $5 \%$ skimmed dry milk at room temperature for $1 \mathrm{~h}$, followed by immunostaining with the following primary antibodies overnight at $4^{\circ} \mathrm{C}$ : Mouse anti-human monoclonal IGF-1R (1:1,000 dilution; cat. no. sc-81464; Santa Cruz Biotechnology, Inc.) and GAPDH (1:1,000 dilution; cat. no. sc-59540; both Santa Cruz Biotechnology, Inc., Dallas, TX, USA). The membranes were washed with Tris-buffered saline solution containing $0.1 \%$ Tween 20 and probed with horseradish peroxidase-conjugated secondary antibodies (both 1:5,000 dilution; cat. no. sc-2005 for IGF-1R, cat no. sc-2064 for GAPDH; both Santa Cruz Biotechnology, Inc.) at room temperature for $1 \mathrm{~h}$. Protein 
bands were visualized using a chemiluminescent detection system (Thermo Fisher Scientific, Inc.).

Luciferase report assay. The HEK293T cells were seeded in 24-well plates at 40-50\% confluence and co-transfected with PGL3-IGF-1R-3'UTR Wt or PGL3-IGF-1R-3'UTR Mut, miR-320a mimics or NC, using Lipofectamine 2000. Following $48 \mathrm{~h}$ of transfection, a Dual-Luciferase ${ }^{\circledR}$ Reporter assay system (Promega Corporation, Madison, WI, USA) was used to detect firefly and Renilla luciferase activities using the GLOMAX multimode reader (Promega Corporation). Renilla activity was evaluated as an internal control for firefly activity.

Statistical analysis. SPSS 13 (SPSS, Inc., Chicago, IL, USA) was used for the statistical analysis. Data are presented as the mean \pm standard deviation. A two-tailed P-value of $<0.05$ was considered to indicate a statistically significant difference.

\section{Results}

miR-320a is downregulated in NSCLC tissues and cell lines. In order to investigate the functions of miR-320a in NSCLC cells, the present study first determined the expression level of miR-320a in NSCLC tissues and matched adjacent tissues using RT-qPCR. As demonstrated in Fig. 1A, miR-320a was significantly downregulated in NSCLC tissues compared with that in matched adjacent tissues $(\mathrm{P}=0.006)$. Furthermore, the miR-320a expression level was evaluated in NSCLC cell lines and a normal bronchial epithelial cell line (16HBE). As revealed in Fig. 1B, reduced miR-320a expression levels were also observed in the four NSCLC cell lines compared with that in the 16HBE cell line. These results indicated that miR-320a was frequently downregulated in NSCLC tissues in addition to NSCLC cell lines, and the low expression level may have contributed to the initiation and progression of NSCLC.

Overexpression of $\mathrm{miR}-320 \mathrm{a}$ inhibits the proliferation and invasion of NSCLC cells. In order to investigate the functions of miR-320a in NSCLC, H23 and A549 cells were transfected with miR-320a mimics or NC. The efficiency of the transfection was determined by RT-qPCR. As demonstrated in Fig. 2A, miR-320a was significantly upregulated in miR-320a mimic-transfected H23 and A549 cells compared with cells transfected with NC.

A cell proliferation assay was performed in order to investigate the effect of miR-320a overexpression on the proliferation of the NSCLC cells. As demonstrated in Fig. 2B, the overexpression of miR-320a significantly inhibited cell proliferation in the H23 $(\mathrm{P}=0.016)$ and $\mathrm{A} 549(\mathrm{P}=0.010)$ cells compared with cells transfected with NC. Furthermore, Transwell cell invasion assays were performed in order to investigate the role of miR-320a in NSCLC cell invasion ability. The results revealed that the invasion ability was significantly decreased in $\mathrm{H} 23(\mathrm{P}=0.020)$ and $\mathrm{A} 549(\mathrm{P}=0.026)$ cells transfected with miR-320a mimics compared with cells transfected with NC (Fig. 2C). These results suggested that miR-320a acted as a tumor suppressor in NSCLC.

miR-320a negatively regulates IGF-1R expression by directly binding to its 3'-untranslated region (3'UTR). In order to find
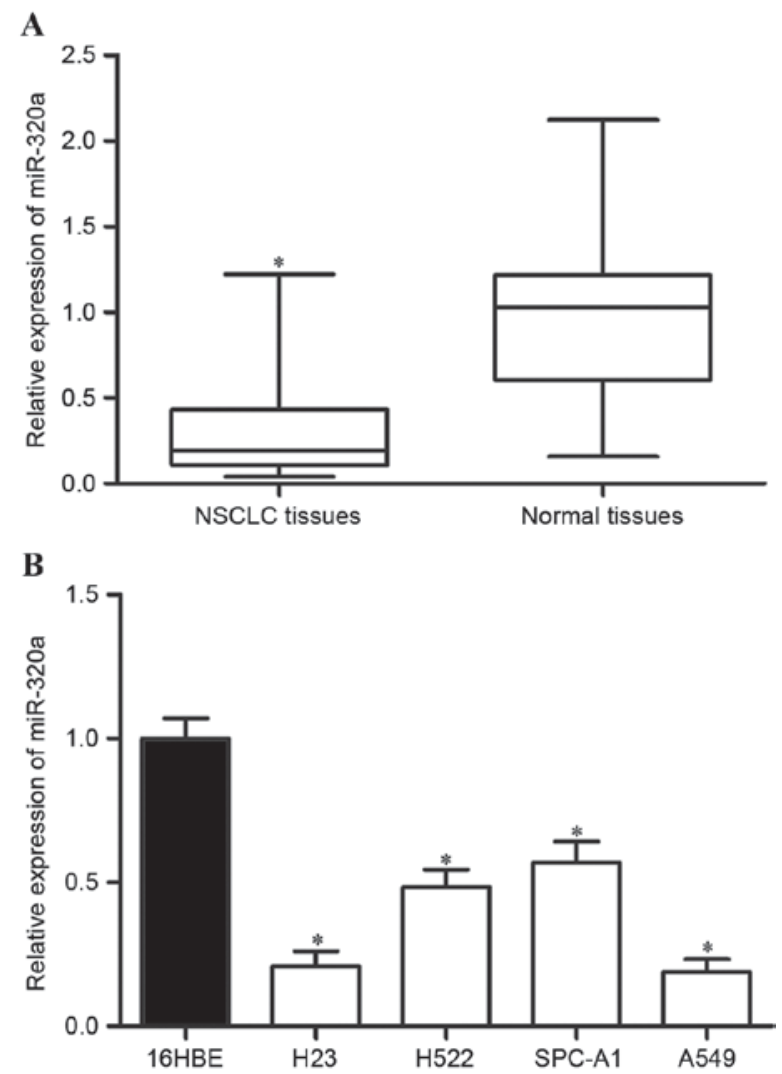

Figure 1. miR-320a expression level is reduced in NSCLC tissues and cell lines. (A) miR-320a expression level in NSCLC tissues and matched adjacent tissues was determined by RT-qPCR. " $\mathrm{P}<0.05$ compared with normal tissues. (B) The expression level of miR-320a in 4 NSCLC cell lines and the normal bronchial epithelial cell line was determined by RT-qPCR. ${ }^{*} \mathrm{P}<0.05$ compared with 16HBE cells. miR-320a, microR NA-320a; NSCLC, non-small cell lung cancer; RT-qPCR, reverse transcription-quantitative polymerase chain reaction.

a potential target gene of miR-320a that may contribute to its suppressive functions in NSCLC cells, bioinformatic analysis was performed. As presented in Fig. 3A, there was complementarity between miR-320a and the 3'UTR region of IGF-1R. The direct regulation of IGF-1R by miR-320a in the NSCLC cells was confirmed by luciferase reporter assay. The luciferase reporter assay demonstrated markedly decreased activity with miR-320a mimics and PGL3-IGF-1R-3'UTR Wt compared with the NC and PGL3-IGF-1R-3'UTR Mut (Fig. 3B).

In addition, RT-qPCR and western blot analysis was performed in order to confirm the regulatory effect of miR-320a on IGF-1R expression level in the NSCLC cells. As demonstrated in Fig. 3C and D, miR-320a mimics decreased the IGF-1R expression level in the H23 and A549 cells at the mRNA and protein levels. Taken together, these results indicated that miR-320a negatively regulated IGF-1R expression by directly binding to its 3'UTR region in the NSCLC cells.

$I G F-1 R$ serves a role in miR-320a-induced functions in NSCLC cells. In order to investigate whether the functions of miR-320a on NSCLC cells were dependent on IGF-1R, the H23 and A549 cells were transfected with IGF-1R siRNA or ctrl siRNA, followed by evaluation by cell proliferation and Transwell cell invasion assays. Firstly, western blot analysis was performed to determine the transfection efficiency. As 

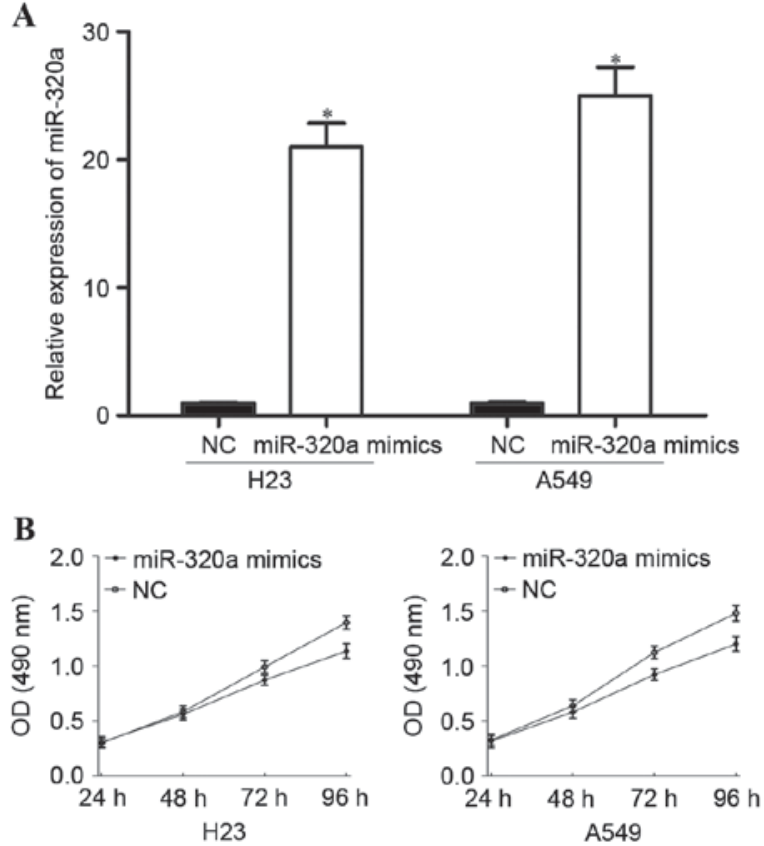

C
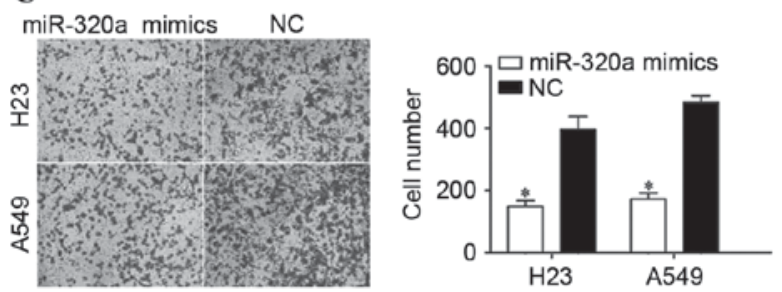

Figure 2. miR-320a inhibits the cell proliferation and invasion of NSCLC cells. (A) The expression levels of miR-320a in H23 and A549 cells transfected with miR-320a mimics or NC were determined by reverse transcription-quantitative polymerase chain reaction. (B) The cell proliferation assay was used to evaluate the proliferation of $\mathrm{H} 23$ and A549 cells following transfection with miR-320a mimics or NC. (C) Transwell cell invasion assay of H23 and A549 cells following transfection with miR-320a mimics or NC; the relative ratio of invasive cells per field is presented. ${ }^{*} \mathrm{P}<0.05$ compared with NC. miR-320a, microRNA-320a; NSCLC, non-small cell lung cancer; $\mathrm{OD}$, optical density; NC, negative control.

presented in Fig. 4A, the IGF-1R expression level was decreased in the H23 and A549 cells following transfection with IGF-1R siRNA. Furthermore, cell proliferation and Transwell cell invasion assays revealed that IGF-1R-knockdown significantly suppressed cell proliferation (Fig. 4B) and invasion (Fig. 4C), compared with the ctrl siRNA groups. These results indicated that the functions of IGF-1R downregulation were similar to the functions induced by miR-320a overexpression in NSCLC cells, rendering IGF-1R as a direct functional target of miR-320a in NSCLC cells.

\section{Discussion}

NSCLC is the leading cause of cancer-associated mortality worldwide and in China (21). There has been progression towards the development of therapeutic treatments for NSCLC patients (22). However, the overall five-year survival rate of NSCLC has remained unfavorable since the 1970s (23). A number of previous studies have demonstrated that miRNAs may be critical regulators in cancer-associated
A

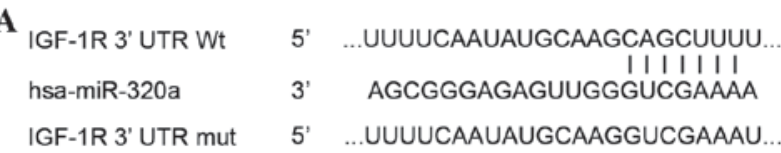

B

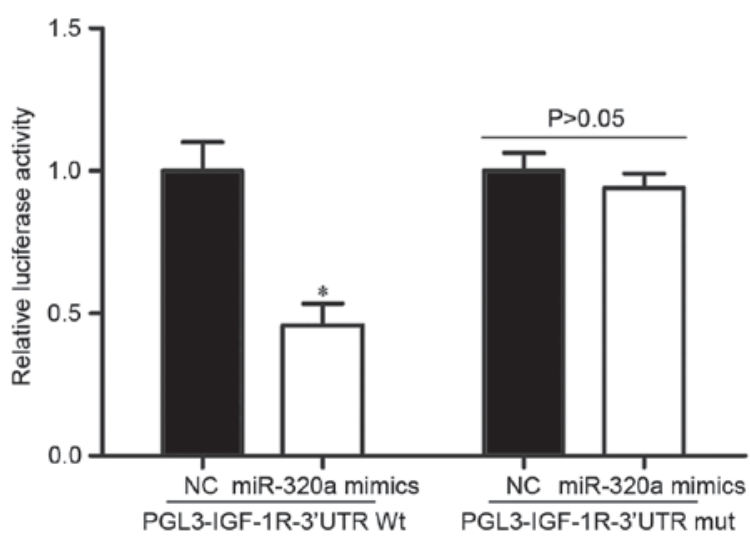

C

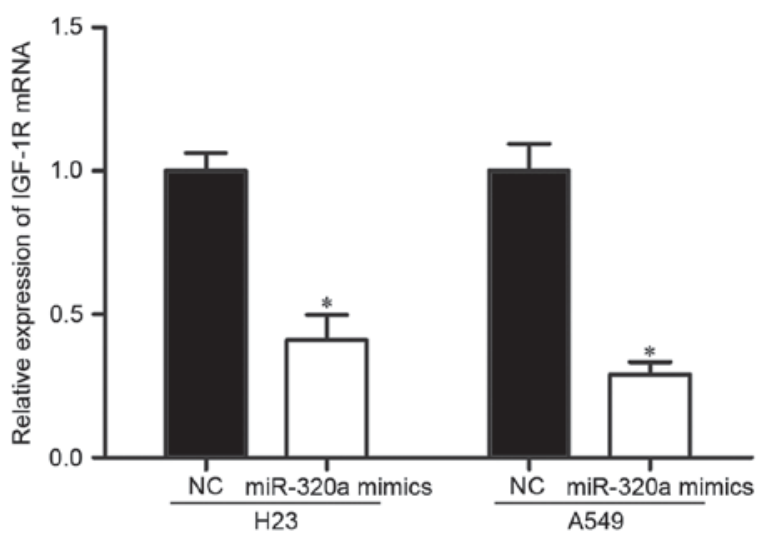

D
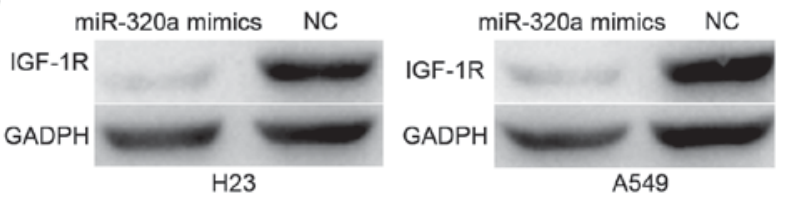

Figure 3. miR-320a negatively regulates IGF-1R expression by directly targeting its $3^{\prime}$ UTR. (A) The predicted binding sites of miR-320a on the 3'UTR of IGF-1R and the mutant IGF-1R 3'UTR sequence at the binding site. (B) The analysis of the relative luciferase activity of PGL3-IGF-1R-3'UTR Wt and PGL3-IGF-1R-3'UTR Mut. "P<0.05 compared with NC (C) Relative expression levels of IGF-1R mRNA in H23 and A549 cells transfected with miR-320a mimics or NC. "P $<0.05$ compared with NC (D) IGF-1R protein expression levels were decreased by miR-320a mimics in H23 and A549 cells. miR-320a, microRNA-320a; IGF-1R, insulin-like growth factor 1 receptor; 3'UTR, 3'-untranslated region; Wt, wild-type; mut, mutant; NC, negative control.

processes $(24,25)$. Therefore, understanding the association between NSCLC and abnormal expression levels of miRNAs may be beneficial for the identification of novel efficient therapeutic targets, in order to improve the prognosis and survival rates of patients with NSCLC. The present study demonstrated that miR-320a was downregulated in NSCLC tissues and cell lines. The suppressive functions of miR-320a on the proliferation and invasion of NSCLC cells was demonstrated in the present study, and indicated that miR-320a may be involved in the carcinogenesis and progression of NSCLC. Furthermore, a molecular association between miR-320a and IGF-1R was validated in the NSCLC cells. 
A

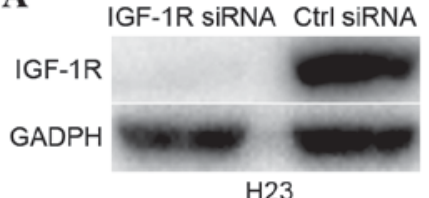

$\mathrm{H} 23$
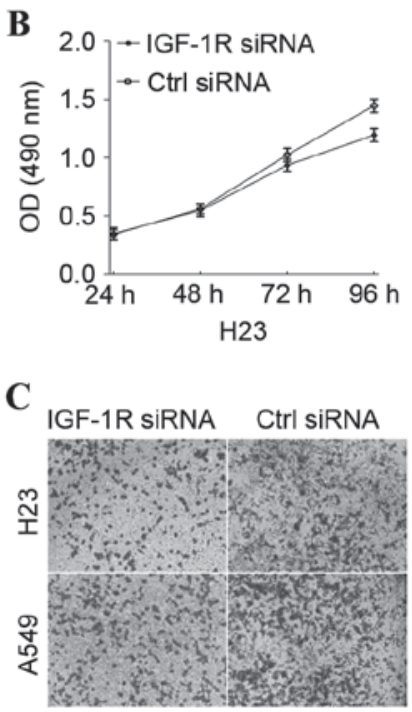
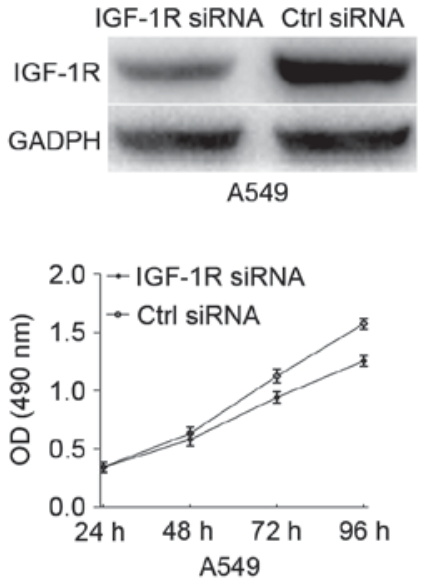

A549

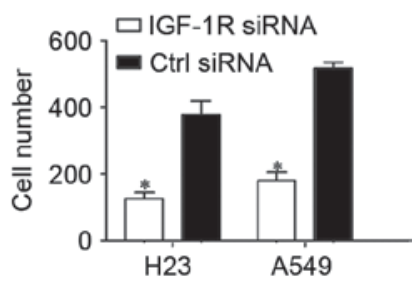

Figure 4. IGF-1R is involved in miR-320a-induced functions in non-small cell lung cancer cells. (A) Relative expression levels of IGF-1R protein in H23 and A549 cells following transfection with IGF-1R siRNA or ctrl siRNA. (B) Downregulation of IGF-1R inhibited the proliferation of H23 and A549 cells. (C) IGF-1R siRNA inhibited the invasion of H23 and A549 cells. ${ }^{*} \mathrm{P}<0.05$ compared with ctrl siRNA. IGF-1R, insulin-like growth factor 1 receptor; miR-320a, microRNA-320a; siRNA, small interfering RNA; ctrl, control; OD, optical density.

The expression levels of miR-320a have been revealed to be reduced in breast cancer (26,27), colon cancer (28), bladder cancer (29), glioblastoma (30) and salivary adenoid cystic carcinoma (31). In breast cancer, miR-320a was downregulated in tumor tissues, and miR-320a expression levels were significantly associated with tumor size, clinical stage, lymph node metastasis and distant metastasis (27). Patients with breast cancer and low expression levels of miR-320a demonstrated shorter overall survival times compared with patients with higher expression levels of miR-320a. Univariate and multivariate analyses revealed that miR-320a was an independent prognostic biomarker for invasive breast cancer $(26,27)$. Sun et al (31) demonstrated that miR-320a expression levels were lower in salivary adenoid cystic carcinoma tissues with metastasis compared with tissues without metastasis. The low expression level of miR-320a indicates a poor prognosis and rapid metastasis for patients with salivary adenoid cystic carcinoma (31). Furthermore, multivariate analysis indicated that miR-320a expression level was an independent indicator of lung metastasis (31). These findings suggested that miR-320a was downregulated in these cancers, and may be a potential prognostic factor.

miR-320a has previously been validated as a tumor suppressor in numerous types of human cancer $(26,28,32)$. For example, in colon cancer, the overexpression of miR-320 inhibited cell proliferation by the downregulation of $\beta$-catenin (28). Zhang et al (32) revealed that miR-320a expression level

restoration suppressed the migration and invasion abilities of colon cancer by directly targeting neuropilin 1 . In breast cancer, re-expression of miR-320a significantly inhibited the proliferation and invasion of breast cancer cells by the blockade of Ras-related protein Rab-11A (26). Lu et al (33) demonstrated that enforced miR-320a expression was sufficient to sensitize tamoxifen-resistant breast cancer cells to tamoxifen by targeting the cyclic adenosine 3', 5'-monophosphate-regulated phosphoprotein and estrogen-related receptor $\gamma$, in addition to their downstream effectors, c-Myc and Cyclin D1. In chronic myeloid leukemia, miR-320a suppressed K562 cell growth and metastasis, and enhanced apoptosis by directly targeting BCR, RhoGEF and GTPase activating protein/ABL proto-oncogene 1, non-receptor tyrosine kinase (34). Qi et al (35) revealed that the upregulation of miR-320a significantly decreased nasopharyngeal carcinoma cell proliferation, migration and invasion in vitro, and tumor growth in vivo by negative regulation of B cell-specific Moloney murine leukemia virus integration site 1 . Together these findings suggested that miR-320a acts as a tumor suppressor, and may be worthy of investigation as a potential anticancer drug for these cancer types.

Identification of cancer-specific miRNAs, in addition to their target genes, is important for elucidating the functions of miRNAs in carcinogenesis and may provide promising therapeutic targets. In the present study, IGF-1R was identified as a direct target gene of miR-320a in NSCLC cells. Firstly, it was revealed that miR-320a could target the 3'UTR sequence of IGF-1R by performing bioinformatic analysis. Furthermore, the luciferase reporter assay demonstrated that miR-320a suppressed the luciferase activity in cells transfected with PGL3-IGF-1R-3'UTR Wt compared with PGL3-IGF-1R-3'UTR Mut, indicating that miR-320a directly targeted the 3'UTR of IGF-1R. Additionally, the overexpression of miR-320a reduced the IGF-1R expression level in NSCLC cells at the mRNA and protein levels. Finally, knockdown of IGF-1R by siRNA had similar effects compared with miR-320a overexpression in NSCLC cells, which demonstrated that IGF-1R was the direct functional target of miR-320a in NSCLC cells. IGF-1R is a transmembrane tyrosine kinase receptor that contains two extracellular $\alpha$ subunits and two transmembrane $\beta$ subunits (27). Previous functional studies have revealed that IGF-1R serves important functions in numerous cancer-associated biological processes, including cell proliferation, anti-apoptosis, vascularization, migration, invasion and metastasis $(36,37)$. Together these findings suggested that IGF-1R is worth paying close attention to as a potential target for the inhibition of NSCLC.

In conclusion, the present study demonstrated that miR-320a was downregulated in NSCLC tissues and cell lines. Overexpression of miR-320a inhibited the proliferation and invasion of NSCLC cells by directly binding to the IGF-1R 3'UTR in vitro. In the future, the aberrant expression of miR-320a may be utilized in therapeutic interventions for patients with NSCLC.

\section{Acknowledgements}

The present study was supported by The National Natural Science Fund (grant no. 81472744). 


\section{References}

1. Shi WY, Liu KD, Xu SG, Zhang JT, Yu LL, Xu KQ and Zhang TF: Gene expression analysis of lung cancer. Eur Rev Med Pharmacol Sci 18: 217-228, 2014.

2. Siegel RL, Miller KD and Jemal A: Cancer statistics, 2015. CA Cancer J Clin 65: 5-29, 2015.

3. Boffetta $\mathrm{P}$ and Nyberg F: Contribution of environmental factors to cancer risk. Br Med Bull 68: 71-94, 2003.

4. Didkowska J, Manczuk M, McNeill A, Powles J and Zatonski W: Lung cancer mortality at ages 35-54 in the European Union: Ecological study of evolving tobacco epidemics. BMJ 331: 189-191, 2005.

5. Ridge CA, McErlean AM and Ginsberg MS: Epidemiology of lung cancer. Semin Intervent Radiol 30: 93-98, 2013.

6. Paliogiannis P, Attene F, Cossu A, Budroni M, Cesaraccio R, Tanda F, Trignano M and Palmieri G: Lung cancer epidemiology in North Sardinia, Italy. Multidiscip Respir Med 8: 45, 2013.

7. Zhang B, Liu T, Wu T, Wang Z, Rao Z and Gao J: microRNA-137 functions as a tumor suppressor in human non-small cell lung cancer by targeting SLC22A18. Int J Biol Macromol 74: 111-118, 2015.

8. Youlden DR, Cramb SM and Baade PD: The International Epidemiology of lung cancer: Geographical distribution and secular trends. J Thorac Oncol 3: 819-831, 2008.

9. Yoda S, Soejima K, Hamamoto J, Yasuda H, Nakayama S, Satomi R, Terai H, Ikemura S, Sato T, Naoki K and Betsuyaku T: Claudin-1 is a novel target of miR-375 in non-small-cell lung cancer. Lung Cancer 85: 366-372, 2014.

10. Sanchez de Cos J, Sojo Gonzélez MA, Montero MV, Pérez Calvo MC, Vicente MJ and Valle MH: Non-small cell lung cancer and silent brain metastasis. Survival and prognostic factors. Lung Cancer 63: 140-145, 2009.

11. Crino L, Weder W, van Meerbeeck J and Felip E; ESMO Guidelines Working Group: Early stage and locally advanced (non-metastatic) non-small-cell lung cancer: ESMO clinical practice guidelines for diagnosis, treatment and follow-up. Ann Oncol 21 (Suppl 5): v103-v115, 2010.

12. Bartel DP: MicroRNAs: Genomics, biogenesis, mechanism, and function. Cell 116: 281-297, 2004.

13. Lewis BP, Shih IH, Jones-Rhoades MW, Bartel DP and Burge CB Prediction of mammalian microRNA targets. Cell 115: 787-798, 2003.

14. Ambros V: The functions of animal microRNAs. Nature 431: 350-355, 2004.

15. Broderick JA and Zamore PD: MicroRNA therapeutics. Gene Ther 18: 1104-1110, 2011.

16. Yu G, Jia Z and Dou Z: miR-24-3p regulates bladder cancer cell proliferation, migration, invasion and autophagy by targeting DEDD. Oncol Rep 37: 1123-1131, 2017.

17. Zu C, Liu T and Zhang G: MicroRNA-506 inhibits malignancy of colorectal carcinoma cells by targeting LAMC1. Ann Clin Lab Sci 46: 666-674, 2016.

18. Bao J, Zou JH, Li CY and Zheng GQ: miR-194 inhibits gastric cancer cell proliferation and tumorigenesis by targeting KDM5B. Eur Rev Med Pharmacol Sci 20: 4487-4493, 2016.

19. Qi Z, Cai S, Cai J, Chen L, Yao Y, Chen L and Mao Y: miR-491 regulates glioma cells proliferation by targeting TRIM28 in vitro. BMC Neurol 16: 248, 2016.
20. Livak KJ and Schmittgen TD: Analysis of relative gene expression data using real-time quantitative PCR and the 2(-Delta Delta C(T)) Method. Methods 25: 402-408, 2001.

21. Siegel R, Naishadham D and Jemal A: Cancer statistics, 2013. CA Cancer J Clin 63: 11-30, 2013.

22. Heist RS: First-line systemic therapy for non-small cell lung cancer. Hematol Oncol Clin North Am 31: 59-70, 2017.

23. Ge H, Li B, Hu WX, Li RJ, Jin H, Gao MM and Ding CM: MicroRNA-148b is down-regulated in non-small cell lung cancer and associated with poor survival. Int J Clin Exp Pathol 8: 800-805, 2015.

24. Volinia S, Calin GA, Liu CG, Ambs S, Cimmino A, Petrocca F, Visone R, Iorio M, Roldo C, Ferracin M, et al: A microRNA expression signature of human solid tumors defines cancer gene targets. Proc Natl Acad Sci USA 103: 2257-2261, 2006.

25. Mishra PJ and Merlino G: MicroRNA reexpression as differentiation therapy in cancer. J Clin Invest 119: 2119-2123, 2009.

26. Wang B, Yang Z, Wang H, Cao Z, Zhao Y, Gong C, Ma L, Wang X, Hu X and Chen S: MicroRNA-320a inhibits proliferation and invasion of breast cancer cells by targeting RAB11A. Am J Cancer Res 5: 2719-2729, 2015.

27. Yang H, Yu J, Wang L, Ding D, Zhang L, Chu C, Chen Q, $\mathrm{Xu}$ Z, Zou Q and Liu X: miR-320a is an independent prognostic biomarker for invasive breast cancer. Oncol Lett 8: 1043-1050, 2014.

28. Sun JY, Huang Y, Li JP, Zhang X, Wang L, Meng YL, Yan B, Bian YQ, Zhao J, Wang WZ, et al: MicroRNA-320a suppresses human colon cancer cell proliferation by directly targeting $\beta$-catenin. Biochem Biophys Res Commun 420: 787-792, 2012.

29. Shang C, Zhang H, Guo Y, Hong Y, Liu Y and Xue Y: MiR-320a down-regulation mediates bladder carcinoma invasion by targeting ITGB3. Mol Biol Rep 41: 2521-2527, 2014.

30. Guo T, Feng Y, Liu Q, Yang X, Jiang T, Chen Y and Zhang Q: MicroRNA-320a suppresses in GBM patients and modulates glioma cell functions by targeting IGF-1R. Tumour Biol 35: $11269-11275,2014$

31. Sun L, Liu B, Lin Z, Yao Y, Chen Y, Li Y, Chen J, Yu D, Tang Z, Wang B, et al: MiR-320a acts as a prognostic factor and inhibits metastasis of salivary adenoid cystic carcinoma by targeting ITGB3. Mol Cancer 14: 96, 2015

32. Zhang Y, He X, Liu Y, Ye Y, Zhang H, He P, Zhang Q, Dong L, Liu Y and Dong J: microRNA-320a inhibits tumor invasion by targeting neuropilin 1 and is associated with liver metastasis in colorectal cancer. Oncol Rep 27: 685-694, 2012.

33. Lu M, Ding K, Zhang G, Yin M, Yao G, Tian H, Lian J, Liu L, Liang M, Zhu T and Sun F: MicroRNA-320a sensitizes tamoxifen-resistant breast cancer cells to tamoxifen by targeting ARPP-19 and ERR $\gamma$. Sci Rep 5: 8735, 2015.

34. Xishan Z, Ziying L, Jing D and Gang L: MicroRNA-320a acts as a tumor suppressor by targeting BCR/ABL oncogene in chronic myeloid leukemia. Sci Rep 5: 12460, 2015.

35. Qi X, Li J, Zhou C, Lv C and Tian M: MicroRNA-320a inhibits cell proliferation, migration and invasion by targeting BMI-1 in nasopharyngeal carcinoma. FEBS Lett 588: 3732-3738, 2014.

36. Werner $\mathrm{H}$ and LeRoith $\mathrm{D}$ : The role of the insulin-like growth factor system in human cancer. Adv Cancer Res 68: 183-223, 1996.

37. Pollak M: The insulin and insulin-like growth factor receptor family in neoplasia: An update. Nat Rev Cancer 12: 159-169, 2012 . 